Supporting Information

\title{
Real-Time and High-Fidelity Tracking of Lysosomal Dynamics with a Dicyanoisophorone-Based Fluorescent Probe
}

\author{
Jiaxin Hong, Qianhua Li, Qingfeng Xia, and Guoqiang Feng* \\ Key Laboratory of Pesticide and Chemical Biology of Ministry of Education, College of Chemistry, Central China \\ Normal University, 152 Luoyu Road, Wuhan 430079, P. R. China. \\ *Corresponding author.Tel.: +862767862163; E-mail: gf256@mail.ccnu.edu.cn (G. Feng).
}

Table of contents:

1. Experimental General ....................................Page S2-S3

2. Additional Data.............................................Page S3-S18 


\section{Experimental General}

\subsection{Materials and Instrumentation}

Starting materials were purchased from commercial suppliers and used without further purification. The stock solution of DCIP was prepared in HPLC grade DMSO. All other solutions were prepared with double-distilled water. UV-vis and fluorescence spectra were recorded on an Agilent Cary 100 UV-vis spectrophotometer and Agilent Cary Eclipse fluorescence spectrophotometer (with temperature controller), respectively. Standard quartz cuvettes with a $10 \mathrm{~mm}$ lightpath were used for all UV-vis spectra and fluorescent spectra measurements. The $\mathrm{pH}$ was measured by a PB-10 digital $\mathrm{pH}-$ meter (Sartorius). The cell imaging was performed on a Leica TCS SP8 confocal laser scanning microscopy, and the fluorescence analysis of the obtained images was carried out by the software (Leica LAS AF) of the instrument.

\subsection{Cell Culture}

MCF-7 cells were purchased from Procell (Wuhan, China). The cells were propagated in a cell culture flask at $37{ }^{\circ} \mathrm{C}$ under humidified $5 \% \mathrm{CO}_{2}$ atmosphere. Dulbecco's modified eagle medium (DMEM, Gibco) was supplemented with $1 \%$ (Vol \%) penicillin-streptomycin $(10,000 \mathrm{U} / \mathrm{mL}$ penicillin, and $10 \mathrm{mg} / \mathrm{mL}$ streptomycin, HyClone) and 10\% (Vol \%) fetal bovine serum (FBS, Gibco). The culture of HeLa cells was used the same method as the culture of MCF-7 cells. And the culture of LO2 cells used RPMI medium 1640 instead of DMEM as culture medium, and the procedure is the same as culturing MCF-7 cells.

\subsection{The Cell Viability Test by MTT Assay}

MCF-7 cells were seeded in a 96-well plate, and these cells were cultured at $37^{\circ} \mathrm{C}$ with humidified 5\% $\mathrm{CO}_{2}$ for $12 \mathrm{~h}$. The culture medium was replaced with $200 \mu \mathrm{L}$ fresh DMEM containing different concentrations of probe DCIP $(10,8,6,4,2$, and $0 \mu \mathrm{M})$, and further incubation was continued for $24 \mathrm{~h}$. After that, MTT solution ( $20 \mu \mathrm{L}, 5$ $\mathrm{mg} / \mathrm{mL}$ ) was introduced into each well, followed by incubation for another $4 \mathrm{~h}$. Then 
the medium was removed carefully, and $200 \mu \mathrm{L}$ DMSO was added to dissolve the purple crystals. The absorbance at $490 \mathrm{~nm}$ was then monitored by a microplate reader.

\section{Additional Data}

Table S1. A comparison of fluorescent probes for lysosomes.

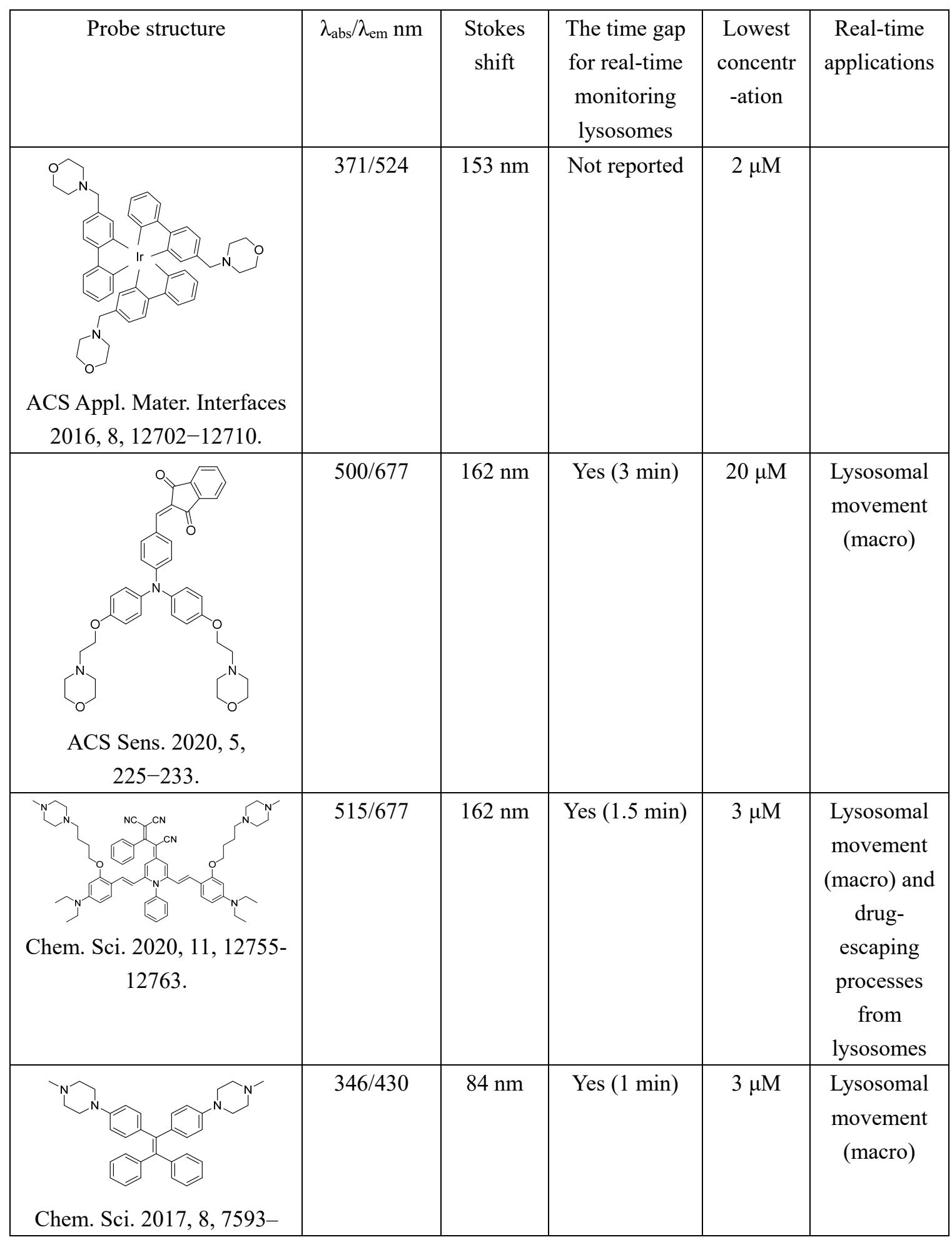




\begin{tabular}{|c|c|c|c|c|c|}
\hline 7603. & & & & & \\
\hline $\begin{array}{c}\text { Chem. Sci. } 2020,11,3152- \\
3163 .\end{array}$ & $383 / 510$ & $127 \mathrm{~nm}$ & Not reported & $2 \mu \mathrm{M}$ & \\
\hline ACS Sens. 2021, 6, 786- & $\begin{array}{c}455- \\
510 / 630- \\
650\end{array}$ & $>150$ & Yes $(10 \mathrm{~s})$ & $0.1 \mu \mathrm{M}$ & $\begin{array}{c}\text { Lysosomal } \\
\text { movement } \\
\text { and } \\
\text { starvation } \\
\text { induced } \\
\text { mitophagy }\end{array}$ \\
\hline Chem. Sci. 2021, 12,9630- & $411 / 538$ & $127 \mathrm{~nm}$ & Not reported & $0.2 \mu \mathrm{M}$ & \\
\hline $\begin{array}{l}\text { Sens. Actuators, B } 2021 \text {, } \\
345,130397 .\end{array}$ & $-/ 655-705$ & - & Not reported & $10 \mu \mathrm{M}$ & \\
\hline This work & $\begin{array}{c}429- \\
490 / 599- \\
684\end{array}$ & $\begin{array}{c}127-244 \\
\mathrm{~nm}\end{array}$ & Yes $(0.44 \mathrm{~s})$ & $\begin{array}{c}0.001 \\
\mu \mathrm{M}\end{array}$ & $\begin{array}{c}\text { Lysosomal } \\
\text { movement, } \\
\text { CCCP } \\
\text { induced } \\
\text { mitophagy } \\
\text { and drug- } \\
\text { escaping } \\
\text { processes } \\
\text { from } \\
\text { lysosomes }\end{array}$ \\
\hline
\end{tabular}


Table S2. The photophysical properties of DCIP in different solvents.

\begin{tabular}{|c|c|c|c|c|}
\hline Solvents & $\lambda_{\text {abs }} / \mathrm{nm}$ & $\lambda_{\mathrm{em}} / \mathrm{nm}$ & Stokes shift/nm & Quantum yield $^{\mathrm{a}}$ \\
\hline Toluene & 472 & 599 & 127 & 0.08 \\
\hline 1,4-Dioxane & 465 & 615 & 150 & 0.20 \\
\hline THF & 478 & 651 & 173 & 0.28 \\
\hline $\mathrm{H}_{2} \mathrm{O}$ & 429 & 653 & 224 & 0.15 \\
\hline Methanol & 459 & 655 & 196 & 0.15 \\
\hline Ethanol & 473 & 663 & 190 & 0.14 \\
\hline Acetone & 474 & 670 & 196 & 0.11 \\
\hline Acetonitrile & 467 & 671 & 204 & 0.07 \\
\hline DMSO & 490 & 684 & 194 & 0.05 \\
\hline
\end{tabular}

${ }^{\mathrm{a}}$ The quantum yield was obtained using Rhodamine B $(\Phi=0.89$ in ethanol $)$ as reference.

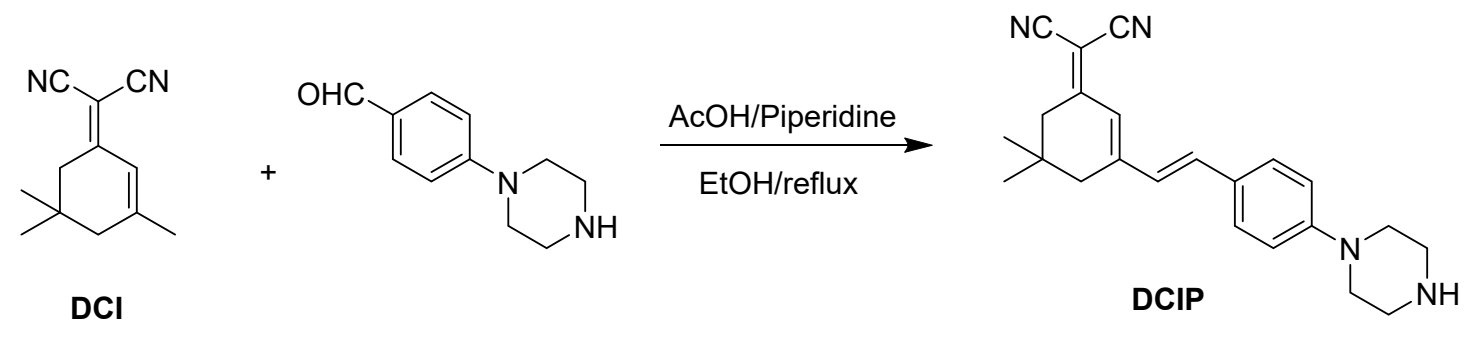

Scheme S1. The synthesis route for DCIP.
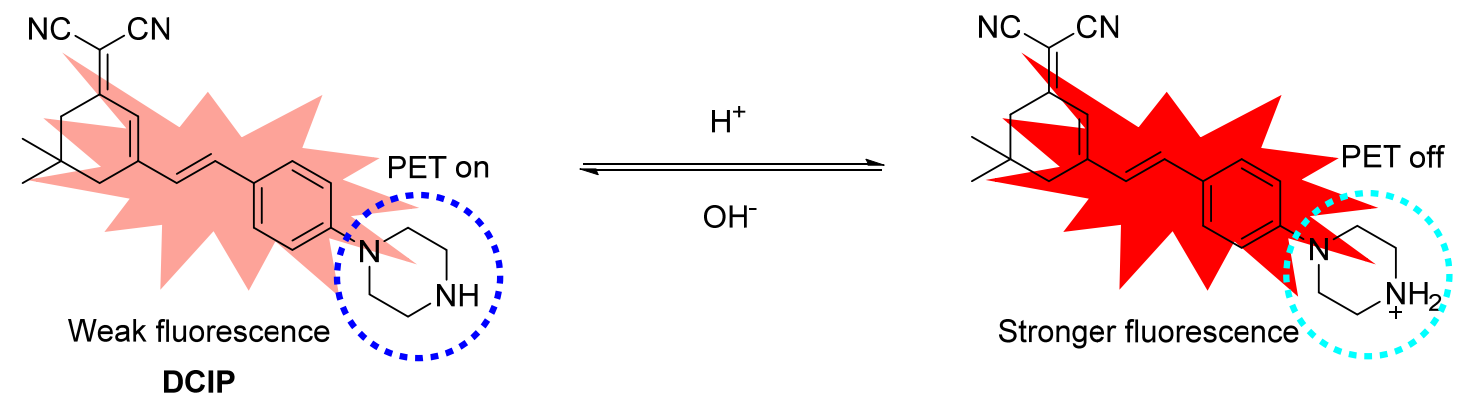

Scheme S2. The effect of $\mathrm{pH}$ to the fluorescence of DCIP. 


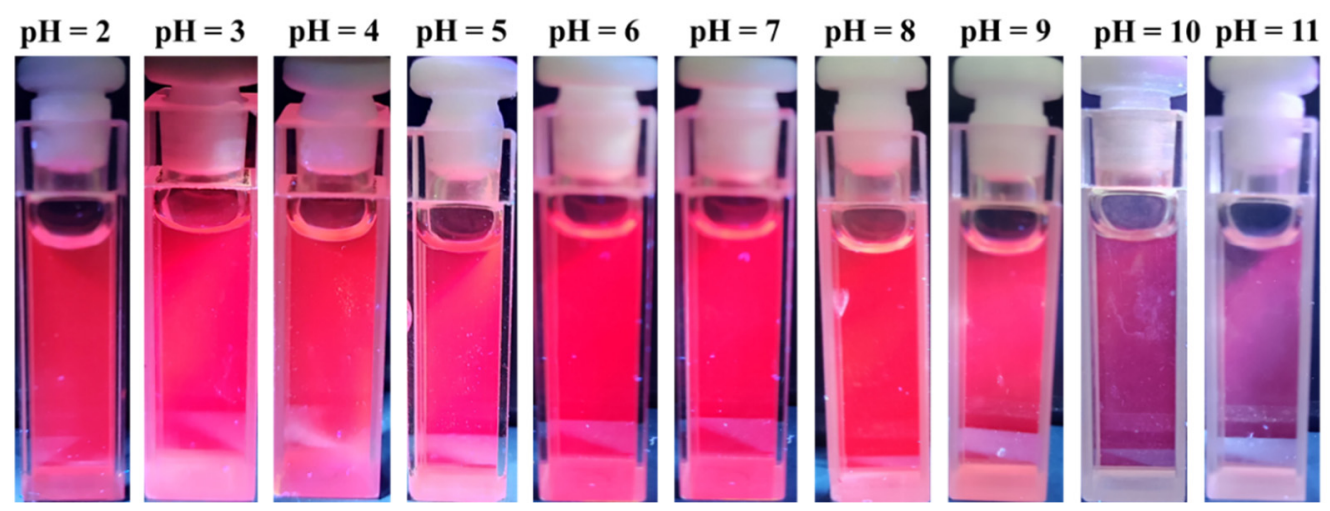

Figure S1. Emission color of probe DCIP $(2 \mu \mathrm{M})$ in the different pH (PBS buffer, 20 $\mathrm{mM})$ at $25{ }^{\circ} \mathrm{C}$ under a $365 \mathrm{~nm}$ light.
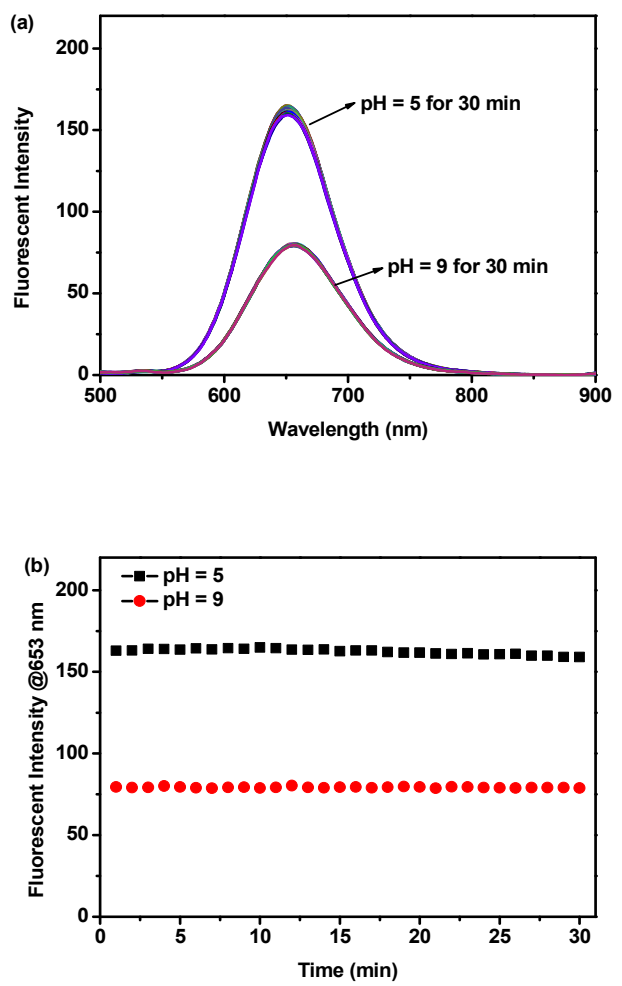

Figure S2. The stability of (a) fluorescent spectra and (b) fluorescent intensity at 653 $\mathrm{nm}$ of DCIP $(2 \mu \mathrm{M})$ at $\mathrm{pH}=5$ and $\mathrm{pH}=9$ (PBS buffer, $20 \mathrm{mM})$. All experiments were performed at $25{ }^{\circ} \mathrm{C}$ with $0.2 \%$ DMSO. $\lambda_{\mathrm{ex}}=454 \mathrm{~nm}$, slit width: $d_{\mathrm{ex}}=5 \mathrm{~nm}, d_{\mathrm{em}}=10$ nm. 

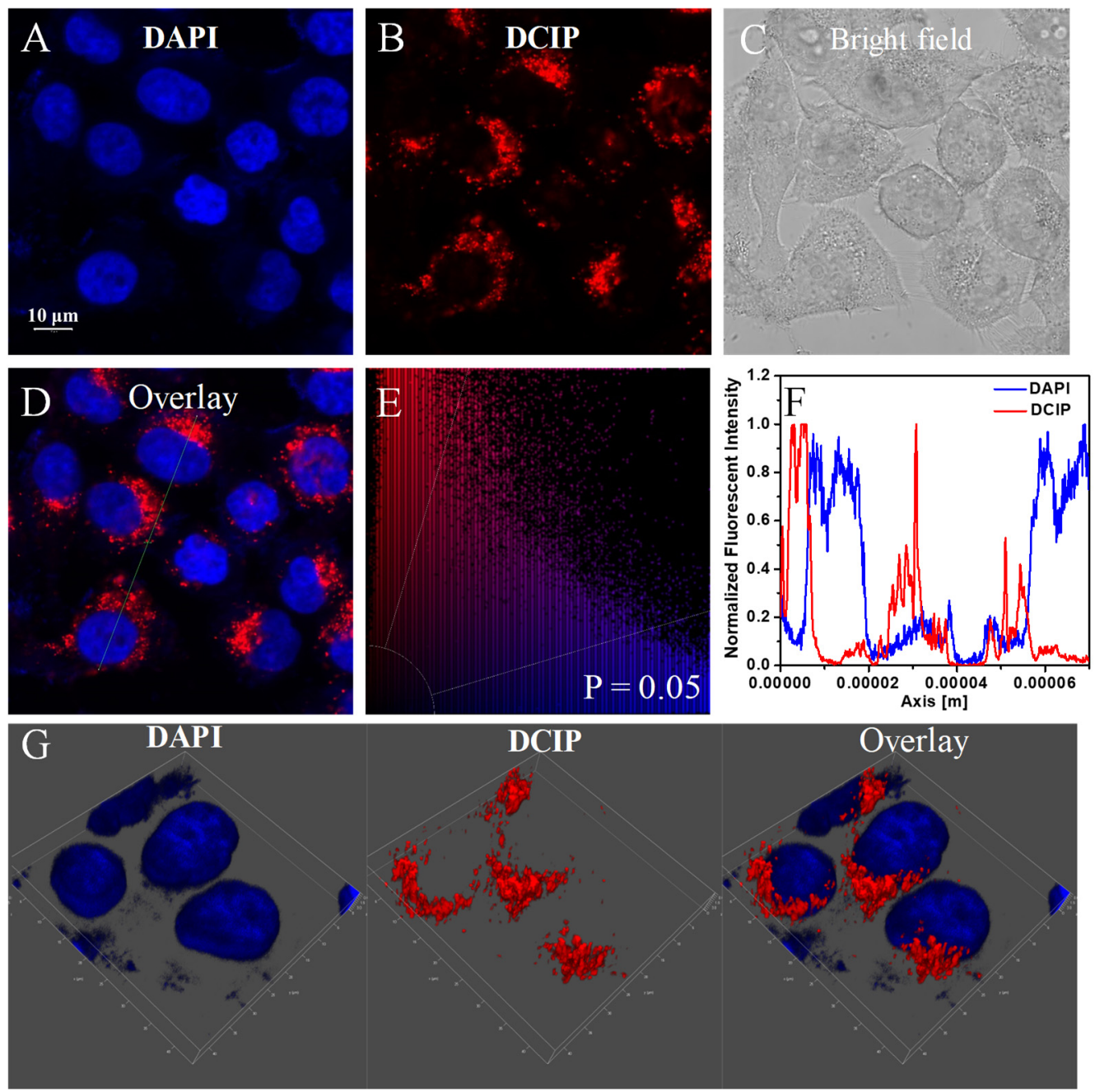

Figure S3. CLSM imaging of MCF-7 cells co-stained with DAPI $(10 \mu \mathrm{g} / \mathrm{mL})$ and DCIP (100 nM). (A) Image of DAPI. (B) Image of DCIP. (C) Bright field image. (D) Overlay of (A) and (B). (E) Scatter plot and Pearson's correlation value of (A) and (B) with data obtained from LAS AF. (F) Intensity correlation of DAPI and DCIP (green line in D). Imaging wavelength for DAPI: $\lambda_{\mathrm{ex}} / \lambda_{\mathrm{em}}=405 / 420-480 \mathrm{~nm} ;$ DCIP: $\lambda_{\mathrm{ex}} / \lambda_{\mathrm{em}}=$ 488/650-700 nm. (G) 3D imaging of nucleus by DAPI and lysosomes by DCIP. 

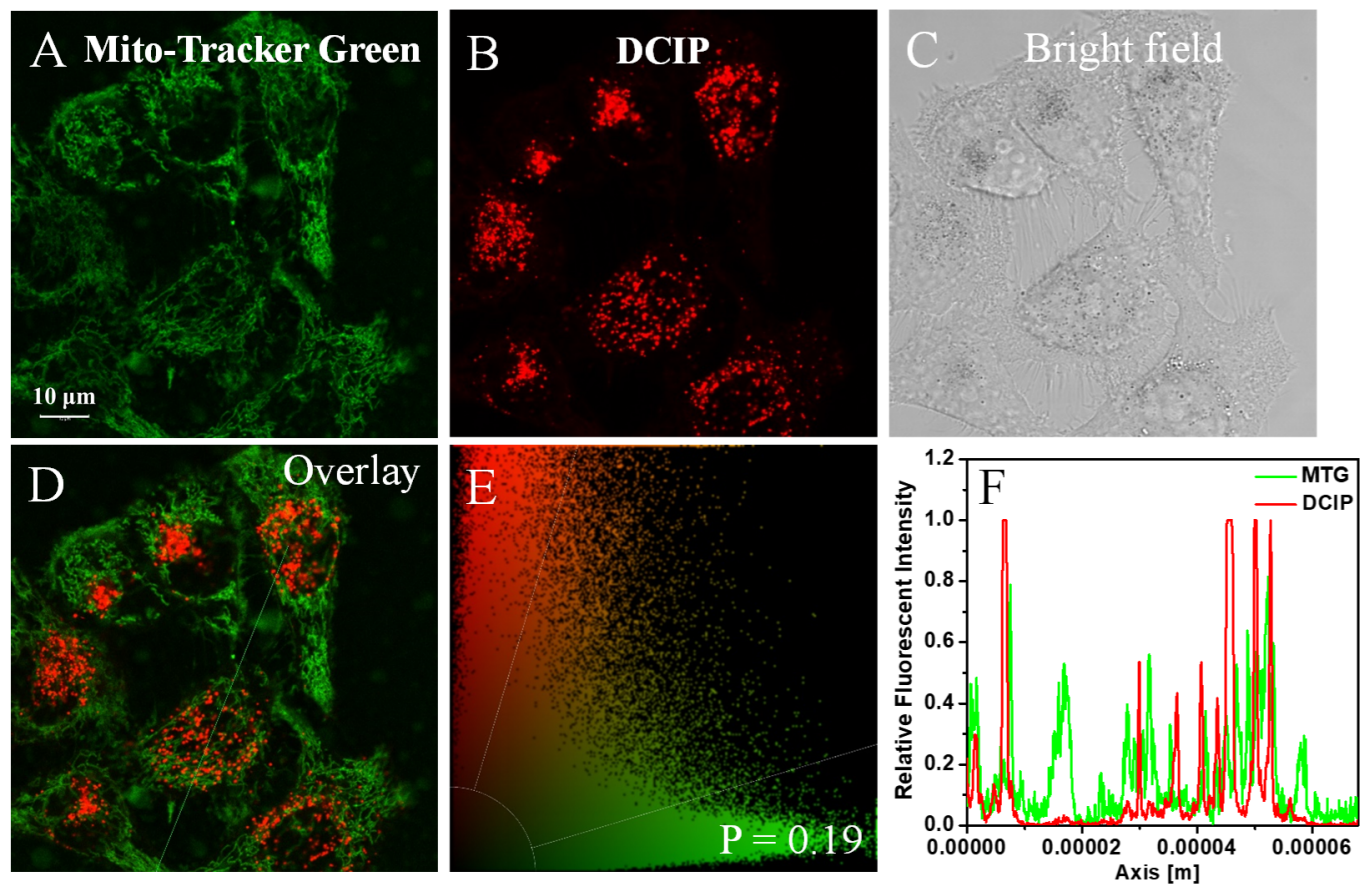

Figure S4. CLSM imaging of MCF-7 cells co-stained with Mito-Tracker green (200 $\mathrm{nM}$ ) and DCIP (100 nM). (A) Image of Mito-Tracker green. (B) Image of DCIP. (C) Bright field image. (D) Overlay of (A) and (B). (E) Scatter plot and Pearson's value of (A) and (B), with data obtained from LAS AF. (F) Intensity correlation of Mito-Tracker Green and DCIP (green line in D). Imaging wavelength: Mito-Tracker Green: $\lambda_{\mathrm{ex}} / \lambda_{\mathrm{em}}$ $=488 / 500-550 \mathrm{~nm}$; DCIP: $\lambda_{\mathrm{ex}} / \lambda_{\mathrm{em}}=488 / 650-700 \mathrm{~nm}$. 

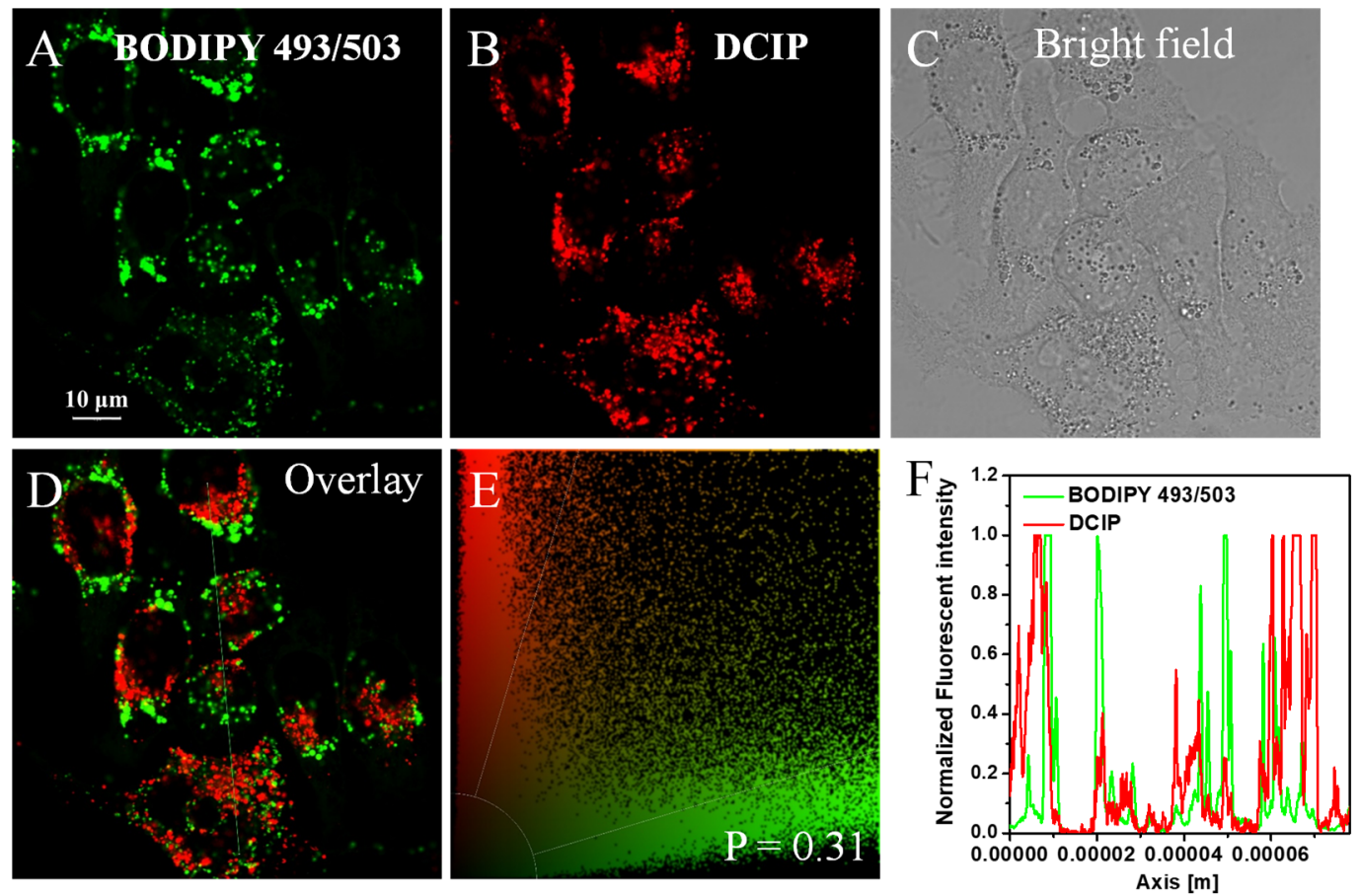

Figure S5. CLSM imaging of MCF-7 cells co-stained with BODIPY 493/503 (200 nM) and DCIP (100 nM). (A) Image of BODIPY 493/503. (B) image of DCIP. (C) Bright field images. (D) Overlay of (A) and (B). (E) Scatter plot and Pearson's value of (A) and (B), with data obtained from LAS AF. (F) Intensity correlation of BODIPY 493/503 and DCIP (green line in D). Imaging wavelength: BODIPY 493/503: $\lambda_{\mathrm{ex}} / \lambda_{\mathrm{em}}=$ 488/500-550 nm; DCIP: $\lambda_{\mathrm{ex}} / \lambda_{\mathrm{em}}=488 / 650-700 \mathrm{~nm}$. 

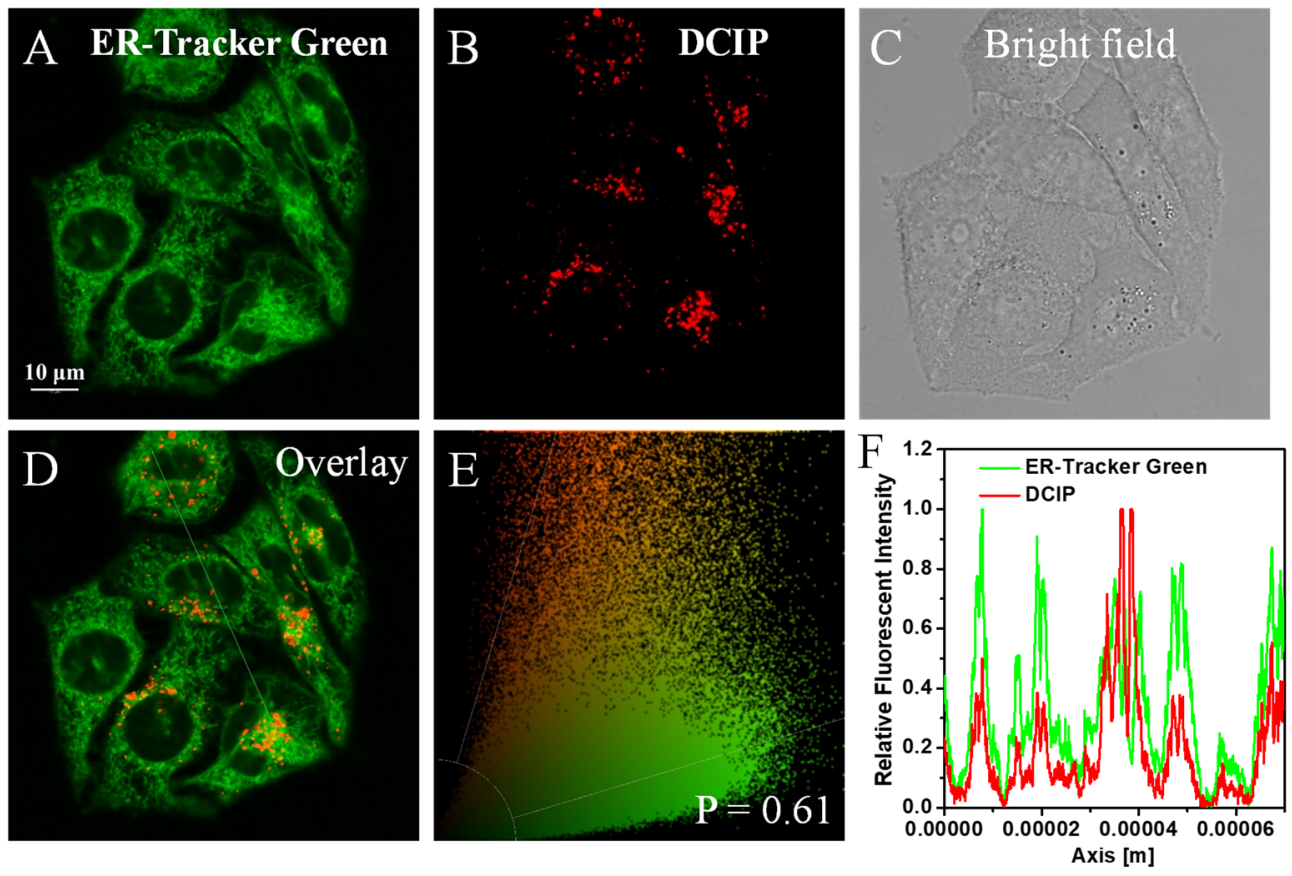

Figure S6. CLSM imaging of MCF-7 cells co-stained with ER-Tracker Green (200 nM) and DCIP (100 nM). (A) Image of ER-Tracker Green. (B) Image of DCIP. (C) Bright field image. (D) Overlay of (A) and (B). (E) Scatter plot and Pearson's value of (A) and (B), with data obtained from LAS AF. (F) Intensity correlation of ER-Tracker Green and DCIP (green line in D). Imaging wavelength: ER-Tracker Green: $\lambda_{\mathrm{ex}} / \lambda_{\mathrm{em}}=$ 488/500-550 nm; DCIP: $\lambda_{\mathrm{ex}} / \lambda_{\mathrm{em}}=488 / 650-700 \mathrm{~nm}$.
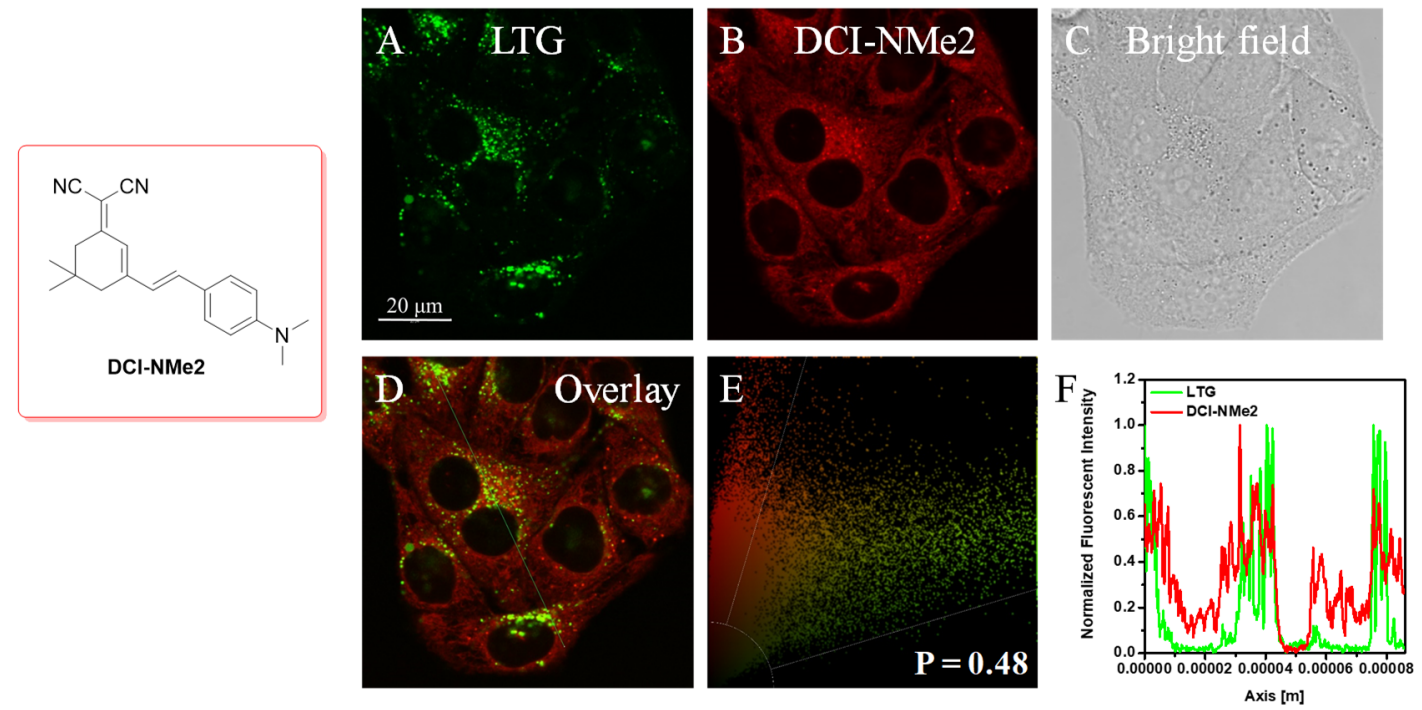

Figure S7. CLSM imaging of MCF-7 cells co-stained with Lyso-Tracker Green (200 $\mathrm{nM}$ ) and DCI-NMe2 (100 nM). (A) Image of Lyso-Tracker Green. (B) Image of DCI- 
NMe2. (C) Bright field image. (D) Overlay of (A) and (B). (E) Scatter plot and Pearson's value of (A) and (B), with data obtained from LAS AF. (F) Intensity correlation of Lyso-Tracker Green and DCI-NMe2 (green line in D). Imaging wavelength: Lyso-Tracker Green: $\lambda_{\mathrm{ex}} / \lambda_{\mathrm{em}}=488 / 500-550 \mathrm{~nm}$; DCI-NMe2: $\lambda_{\mathrm{ex}} / \lambda_{\mathrm{em}}=$ $561 / 660-740 \mathrm{~nm}$.
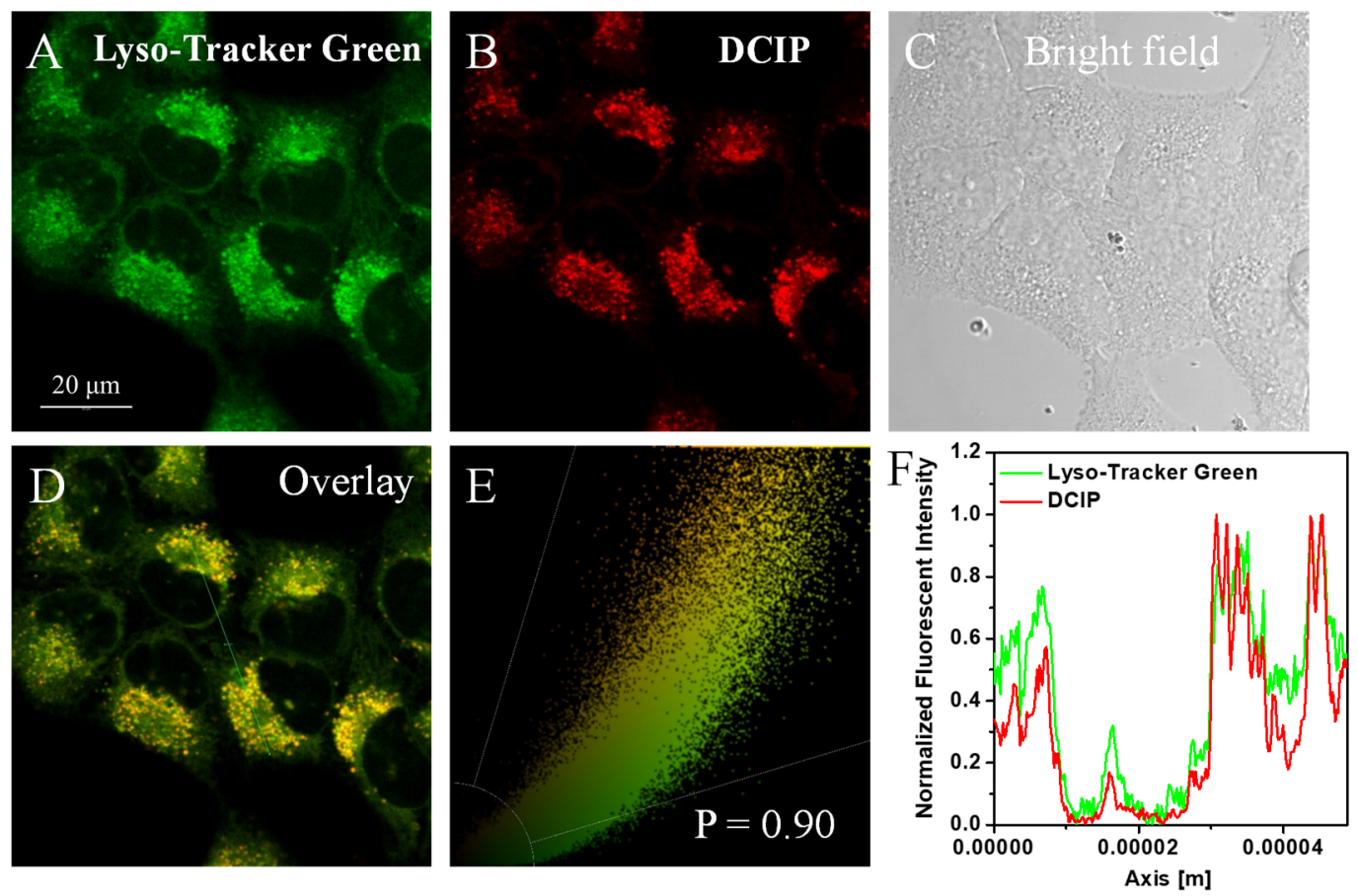

Figure S8. CLSM imaging of HeLa cells co-stained with Lyso-Tracker Green (200 nM) and DCIP (100 nM). (A) Image of Lyso-Tracker Green. (B) Image of DCIP. (C) Bright field image. (D) Overlay of (A) and (B). (E) Scatter plot and Pearson's value of (A) and (B), with data obtained from LAS AF. (F) Intensity correlation of Lyso-Tracker Green and DCIP (green line in D). Imaging wavelength: Lyso-Tracker Green: $\lambda_{\mathrm{ex}} / \lambda_{\mathrm{em}}=$ 488/500-550 nm; DCIP: $\lambda_{\mathrm{ex}} / \lambda_{\mathrm{em}}=488 / 650-700 \mathrm{~nm}$. 

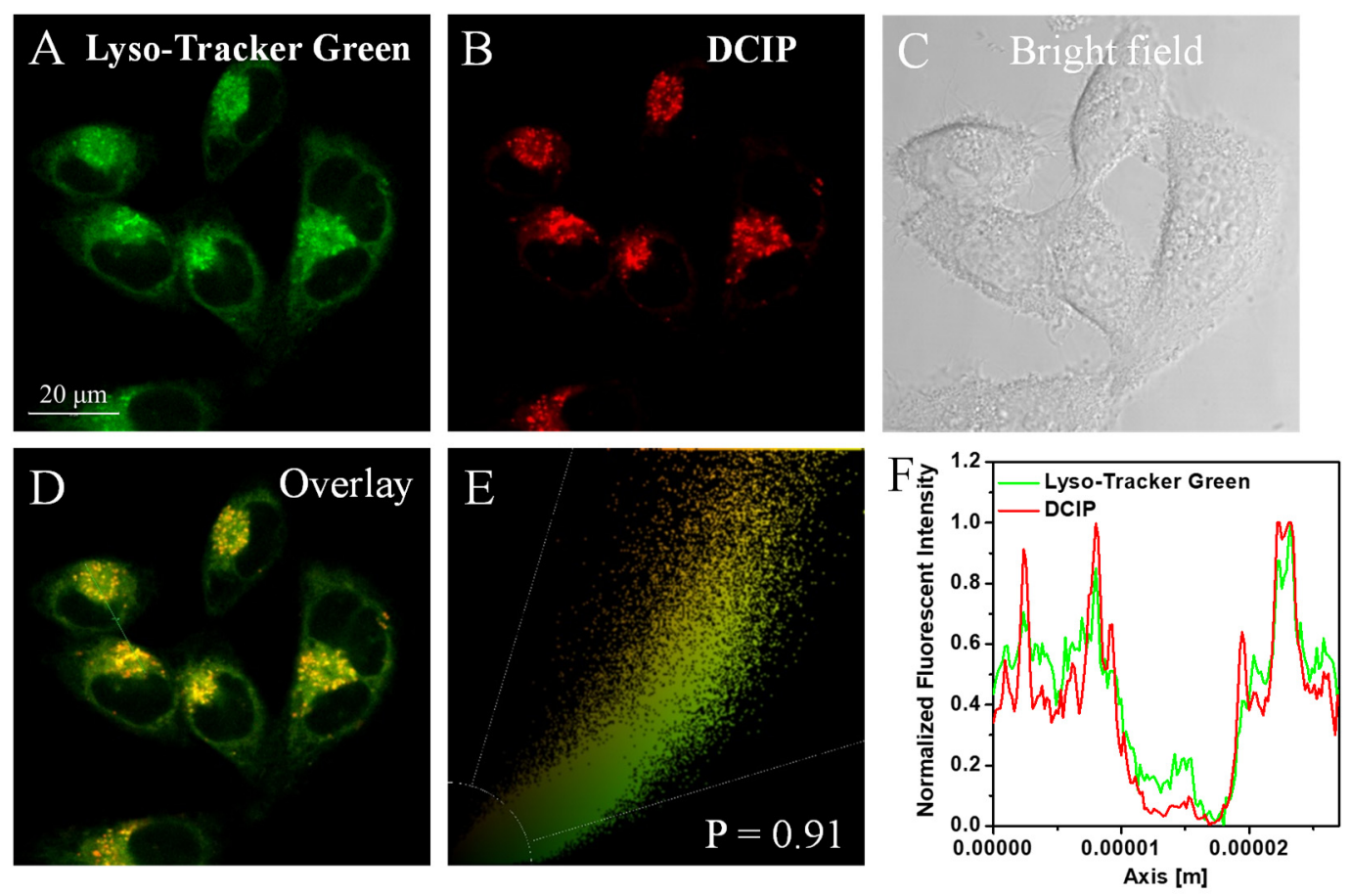

Figure S9. CLSM imaging of LO2 cells co-stained with Lyso-Tracker Green (200 nM) and DCIP (100 nM). (A) Image of Lyso-Tracker Green. (B) Image of DCIP. (C) Bright field image. (D) Overlay of (A) and (B). (E) Scatter plot and Pearson's value of (A) and (B), with data obtained from LAS AF. (F) Intensity correlation of Lyso-Tracker Green and DCIP (green line in D). Imaging wavelength: Lyso-Tracker Green: $\lambda_{\mathrm{ex}} / \lambda_{\mathrm{em}}=$ 488/500-550 nm; DCIP: $\lambda_{\mathrm{ex}} / \lambda_{\mathrm{em}}=488 / 650-700 \mathrm{~nm}$. 


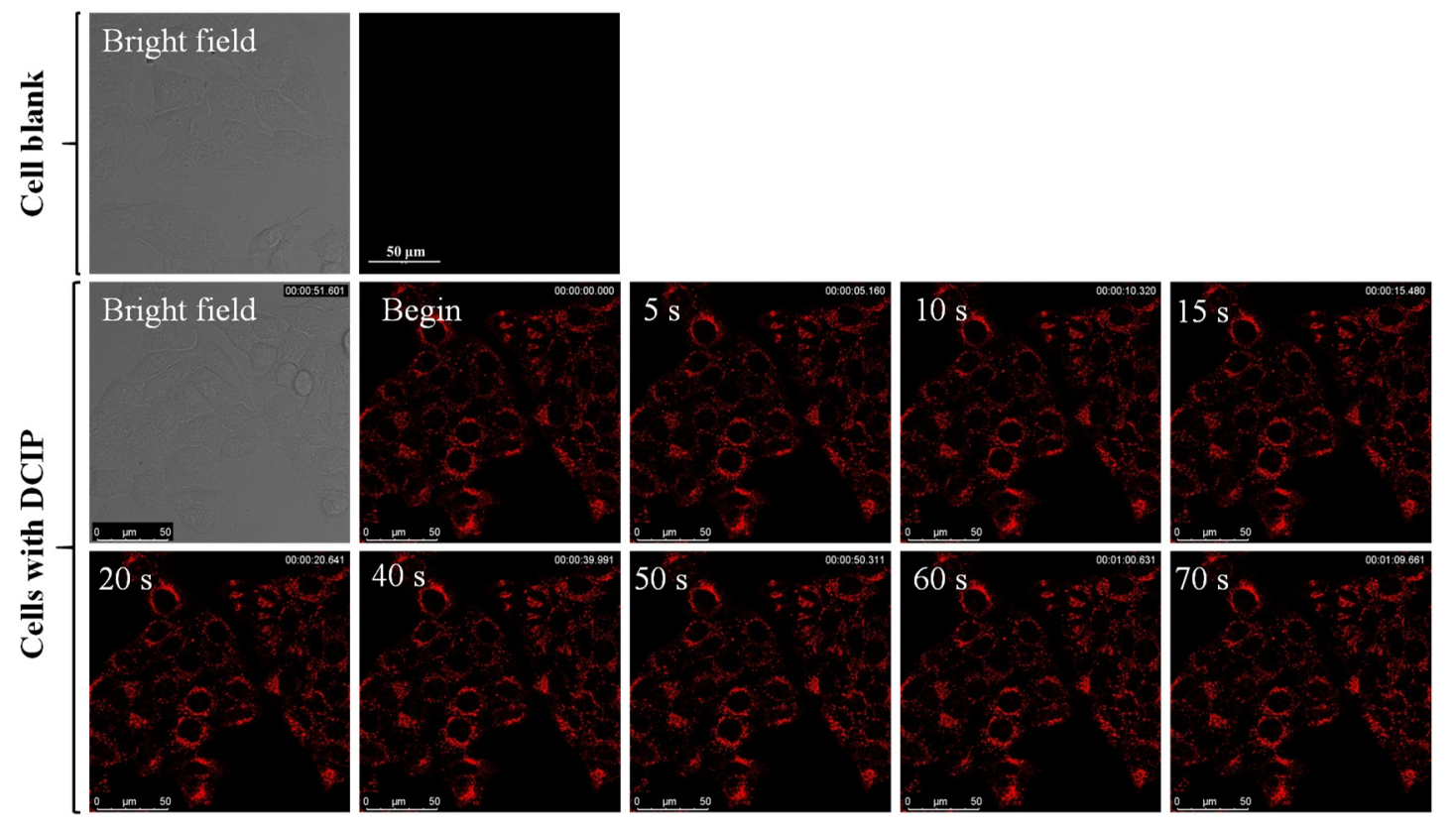

Figure S10. Time-dependent CLSM imaging of DCIP $(100 \mathrm{nM})$ in MCF-7 cells. $\left(1^{\text {st }}\right.$ row) Cell blank. ( $2^{\text {nd }}$ and $3^{\text {rd }}$ row) The cell images at different times after the addition of DCIP (100 nM). Imaging wavelength: $\lambda_{\mathrm{ex}} / \lambda_{\mathrm{em}}=488 \mathrm{~nm} / 650-700 \mathrm{~nm}$.

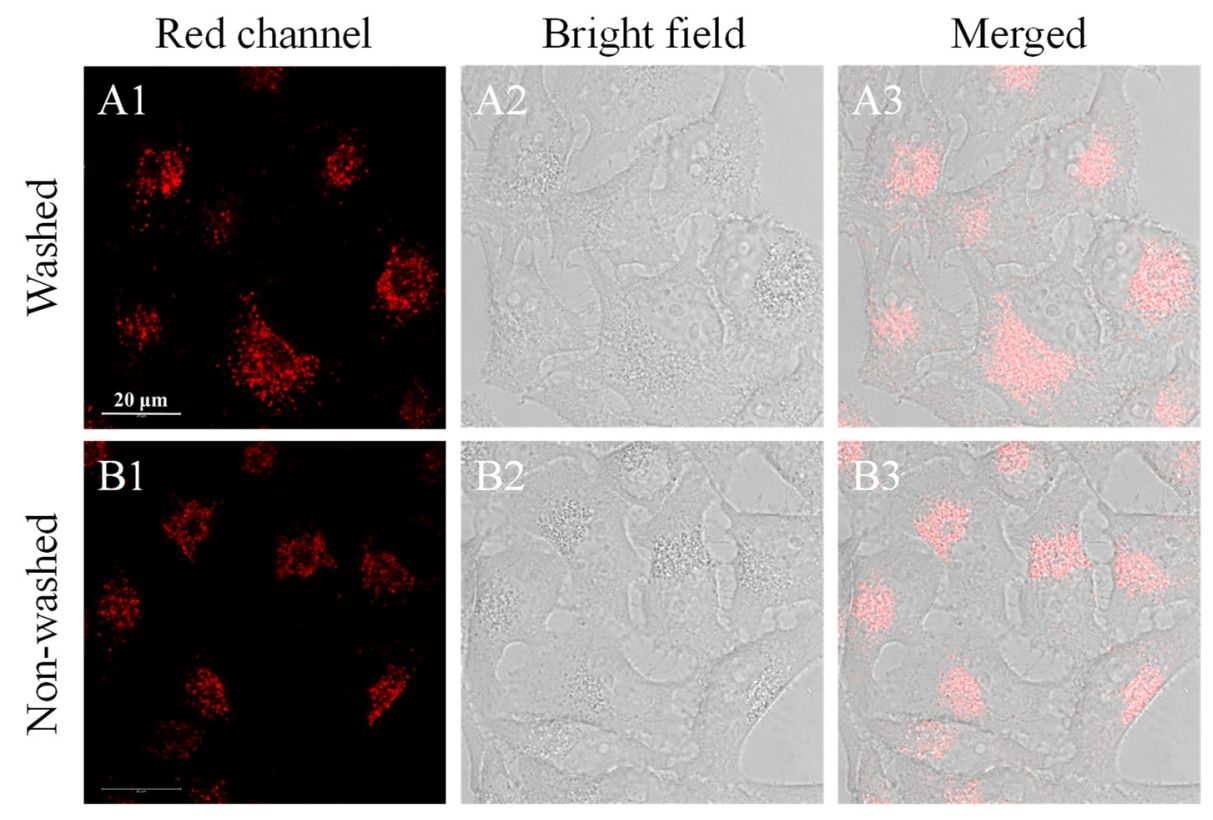

Figure S11. CLSM imaging of DCIP (100 nM) in MCF-7 cells. (A1-A3) The cells were imaged after being washed 3 times with PBS buffer. (B1-B3) The images of nonwashed cells. Imaging wavelength: $\lambda_{\mathrm{ex}} / \lambda_{\mathrm{em}}=488 \mathrm{~nm} / 650-700 \mathrm{~nm}$. 


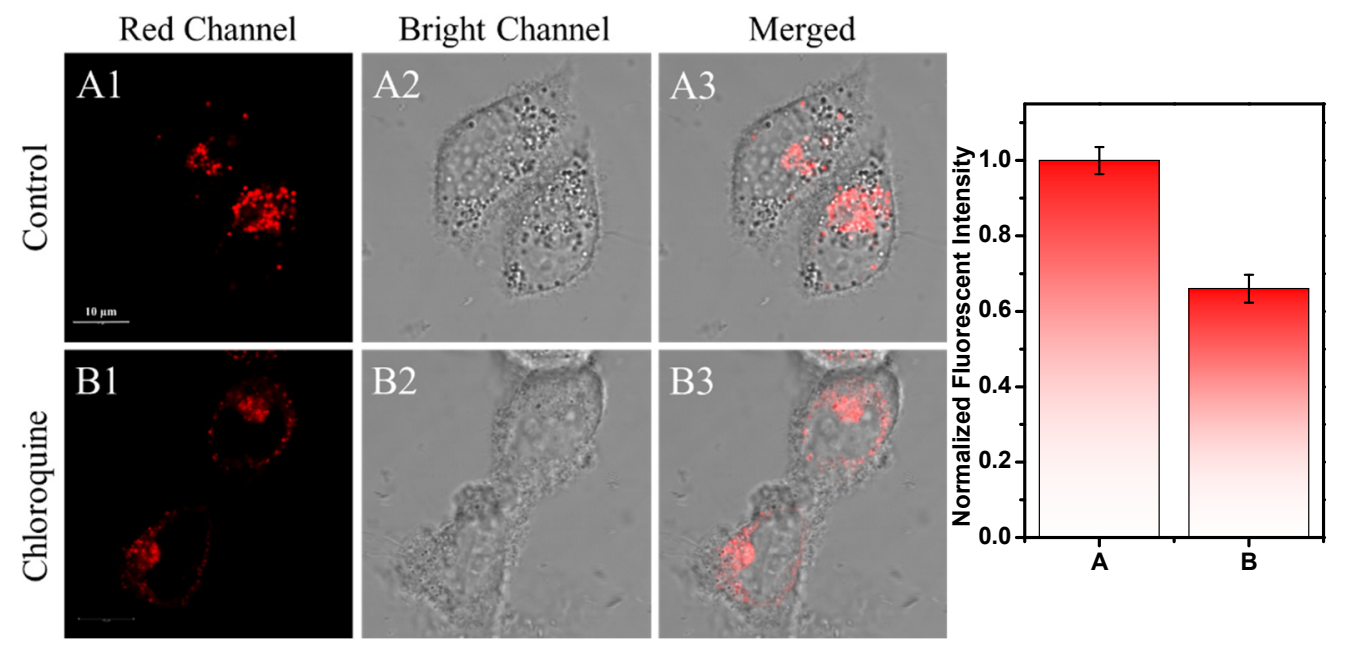

Figure S12. CLSM imaging of MCF-7 cells with 100 nM DCIP. (A1-A3) Cells were incubated with $100 \mathrm{nM}$ DCIP as a control. (B1-B3) Cells were incubated with $50 \mu \mathrm{M}$ chloroquine for $1 \mathrm{~h}$, then incubated with $100 \mathrm{nM}$ DCIP. Imaging wavelength: $\lambda_{\mathrm{ex}} / \lambda_{\mathrm{em}}=$ 488/650-700 nm.

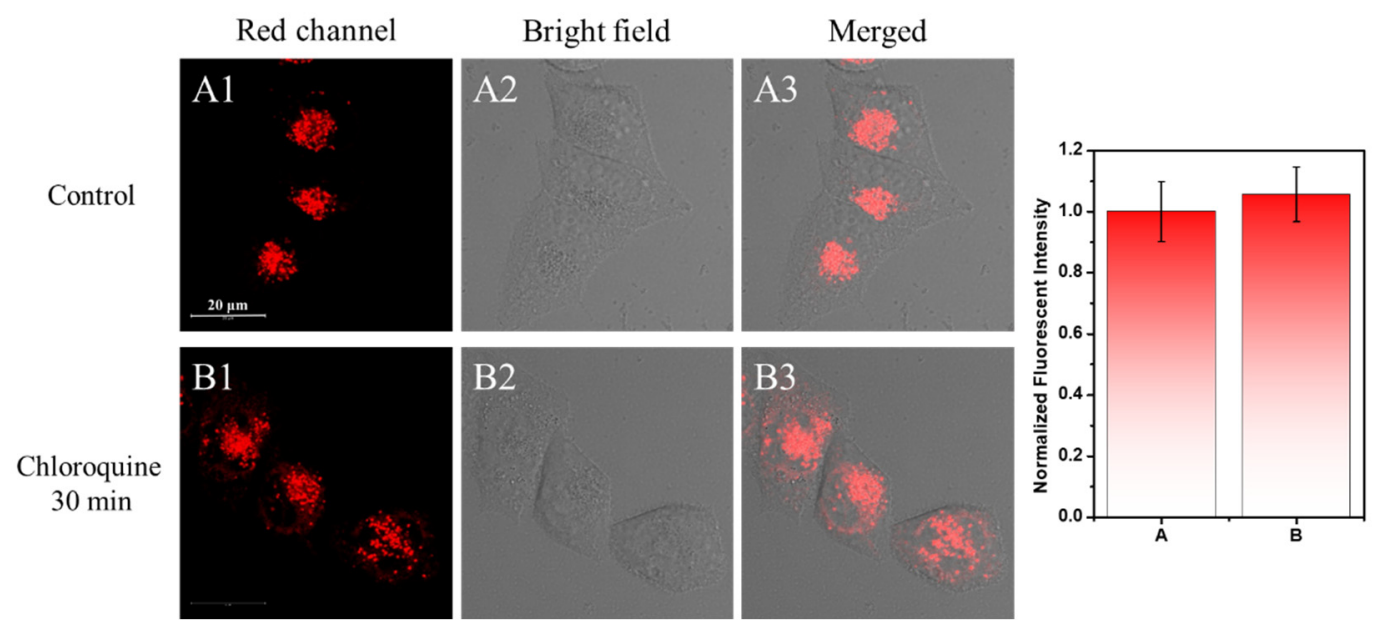

Figure S13. (A1-A3) Cells were incubated with $100 \mathrm{nM}$ DCIP for $10 \mathrm{~min}$ as a control. (B1-B3) Cells were incubated with $5 \mu \mathrm{M}$ chloroquine for $30 \mathrm{~min}$, then incubated with $100 \mathrm{nM}$ DCIP for $10 \mathrm{~min}$. Imaging wavelength: $\lambda_{\mathrm{ex}} / \lambda_{\mathrm{em}}=488 / 650-700 \mathrm{~nm}$. 


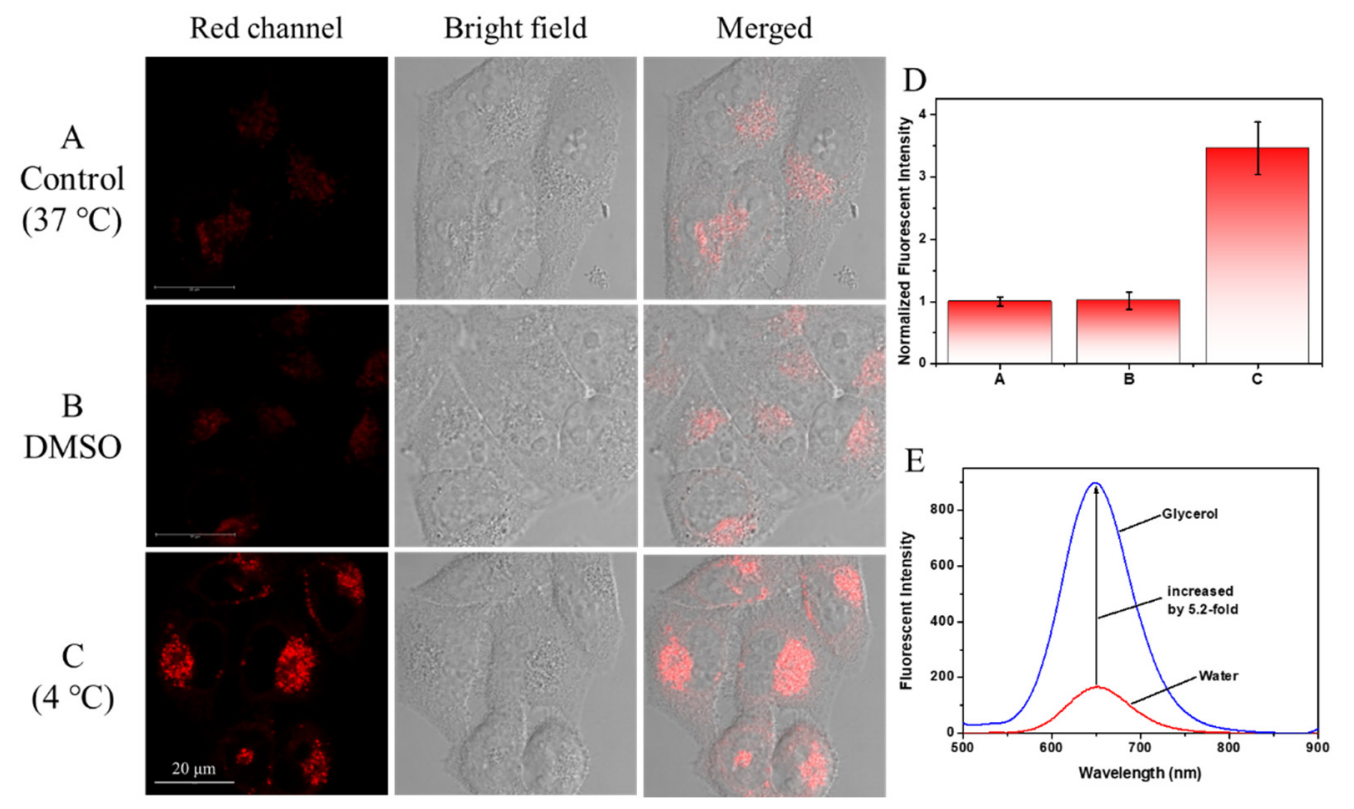

Figure S14. (A) Cells were incubated with DCIP (100 nM) at $37{ }^{\circ} \mathrm{C}$ as control. (B) Cells were incubated with DMSO $(10 \mu \mathrm{L}$ in $1 \mathrm{~mL}$ DMEM) and then treated with DCIP $(100 \mathrm{nM})$ at $37{ }^{\circ} \mathrm{C}$. (C) Cells were incubated with DCIP $(100 \mathrm{nM})$ at $4{ }^{\circ} \mathrm{C}$. (D) The relative fluorescence of $A, B$, and C. $\lambda_{\mathrm{ex}} / \lambda_{\mathrm{em}}=488 / 650-700 \mathrm{~nm}$. (E) The fluorescence spectral of DCIP $(2 \mu \mathrm{M})$ in water and glycerol $\left(\lambda_{\mathrm{ex}}=454 \mathrm{~nm}\right.$, slit width: $d_{\mathrm{ex}}=5 \mathrm{~nm}$, $\left.d_{\mathrm{em}}=10 \mathrm{~nm}\right)$. 


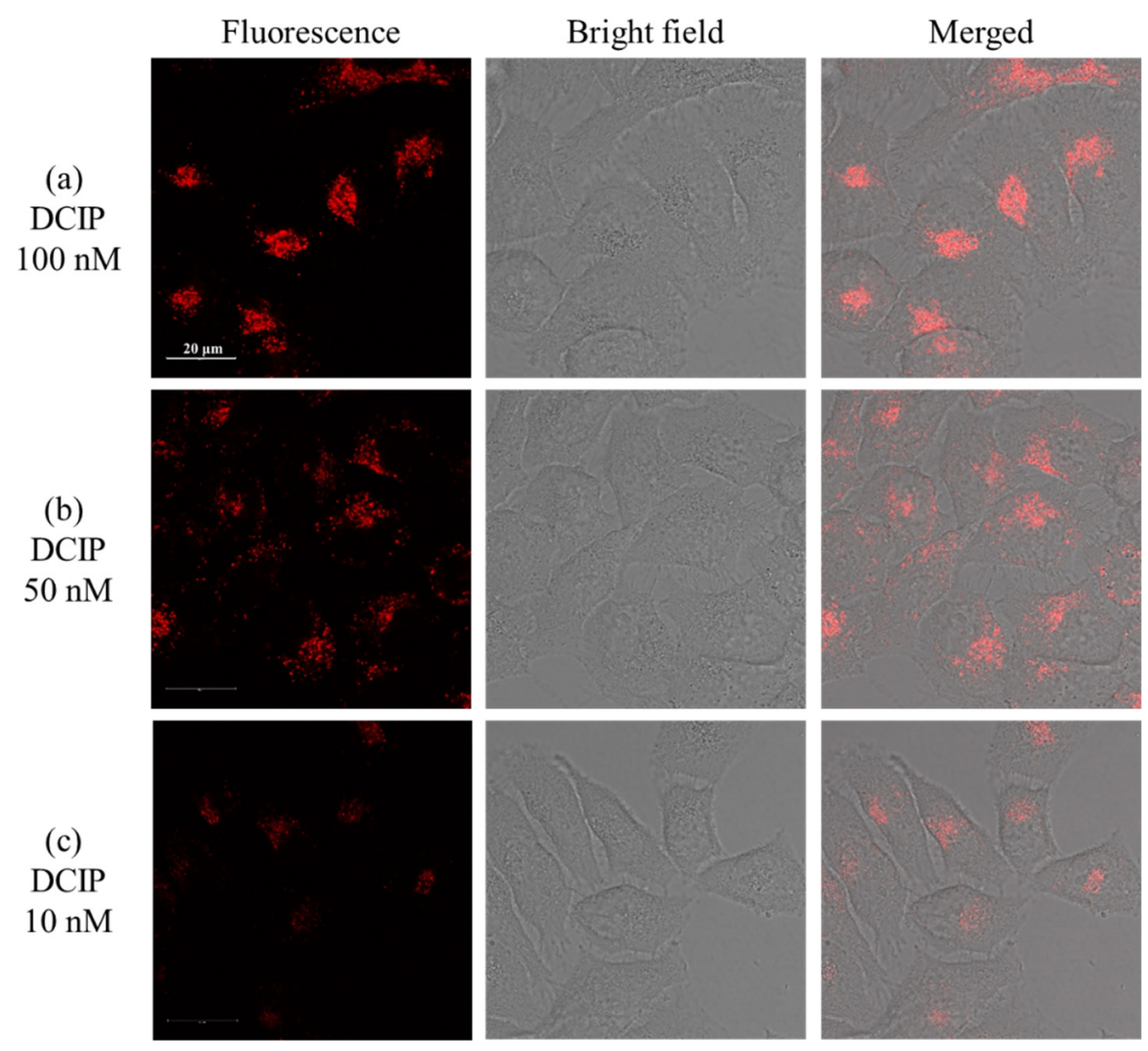

Figure S15. CLSM imaging of MCF-7 cells stained with different concentrations of DCIP: (a) $100 \mathrm{nM}$, (b) $50 \mathrm{nM}$, and (c) $10 \mathrm{nM}$. Imaging wavelength: $\lambda_{\mathrm{ex}} / \lambda_{\mathrm{em}}=488$ $\mathrm{nm} / 650-700 \mathrm{~nm}$. 


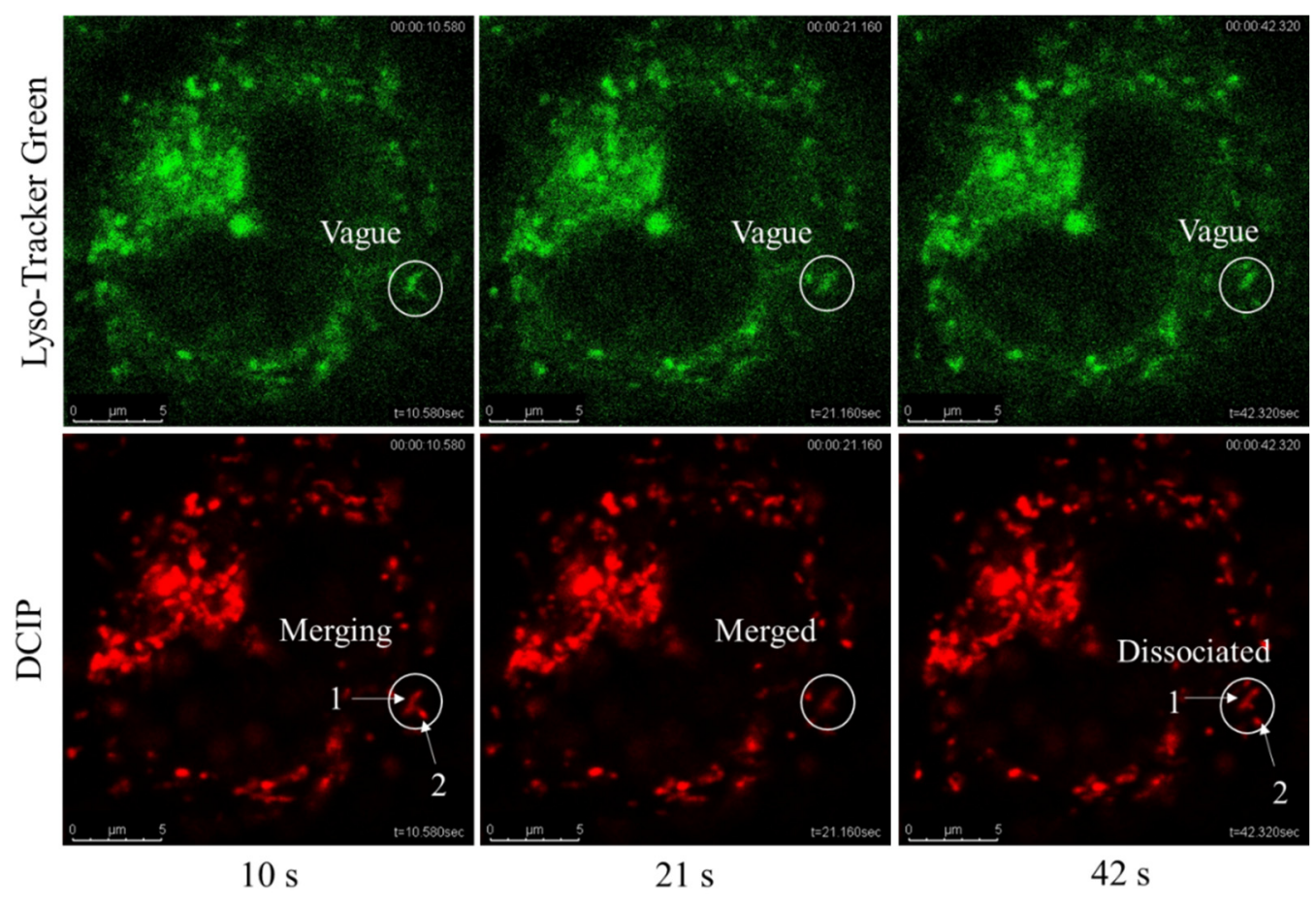

Figure S16. CLSM imaging of the movements of lysosomes. The $1^{\text {st }}$ row: stained by Lyso-Tracker Green $(200 \mathrm{nM})$. The $2^{\text {nd }}$ row: stained by DCIP $(100 \mathrm{nM})$. The exposure time gap was set at 5 s. Imaging wavelength: Lyso-Tracker Green: $\lambda_{\text {ex }} / \lambda_{\mathrm{em}}=$ 488/500-550 nm; DCIP: $\lambda_{\mathrm{ex}} / \lambda_{\mathrm{em}}=488 / 650-700 \mathrm{~nm}$.

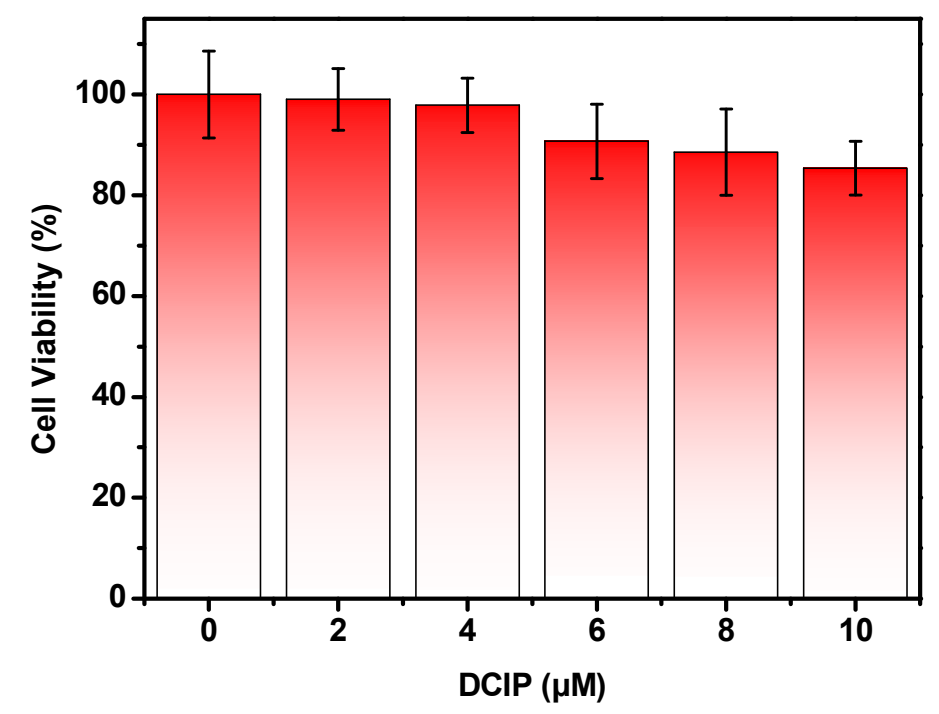

Figure S17. Viable MCF-7 cells after treatment with the indicated concentrations of DCIP after 24 hours. The cell viability was observed via MTT assay. 


\section{Captions of Videos:}

Video S1. Time-dependent CLSM imaging of DCIP (100 nM) after adding to MCF-7 cells; images were captured per $1 \mathrm{~s}$ with an excitation of $488 \mathrm{~nm}$ for a total period of $80 \mathrm{~s}$; imaging wavelength: $\lambda_{\mathrm{ex}} / \lambda_{\mathrm{em}}=488 / 650-700 \mathrm{~nm}$.

Video S2A. Real-time tracking lysosomes in MCF-7 cells stained with DCIP (100 nM); images were captured per $5 \mathrm{~s}$ with an excitation of $488 \mathrm{~nm}$ for a total period of $120 \mathrm{~s}$.

Video S2B. Real-time tracking lysosomes in MCF-7 cells stained with Lyso-Tracker Green $(200 \mathrm{nM})$; images were captured per $5 \mathrm{~s}$ with an excitation of $488 \mathrm{~nm}$ for a total period of $120 \mathrm{~s}$.

Video S3. CLSM HSR imaging of the movement of lysosomes with $1 \mathrm{nM}$ DCIP in MCF-7 cells; images were captured per $0.44 \mathrm{~s}$ with an excitation of $488 \mathrm{~nm}$ for a total period of $65 \mathrm{~s}$.

Video S4. CLSM imaging of the mitochondria-lysosome interactions with DCIP (100 $\mathrm{nM})$ and Mito-Tracker Green $540(200 \mathrm{nM})$ in MCF-7 cells; images captured per $10 \mathrm{~s}$ with an excitation of $488 \mathrm{~nm}$ for a total period of $140 \mathrm{~s}$. 